\section{Case Reports in Dermatology}

\title{
Idiopathic Facial Aseptic Granuloma in a 13-Year-Old Boy Dramatically Improved with Oral Doxycycline and Topical Metronidazole: Evidence for a Link with Childhood Rosacea
}

\author{
Camille Orion $^{a} \quad$ Alicia Sfecci $^{a} \quad$ Laurent Tisseau $^{b} \quad$ Laure Darrieux $^{a}$ \\ Gilles Safa ${ }^{a}$ \\ ${ }^{a}$ Department of Dermatology, Centre Hospitalier de Saint-Brieuc, Saint-Brieuc, France; \\ ${ }^{\mathrm{b}}$ Armor Pathology Laboratory, Plérin, France
}

\section{Keywords}

Idiopathic facial aseptic granuloma - Pediatric rosacea - Facial nodule

\begin{abstract}
Idiopathic facial aseptic granuloma (IFAG) is a rare, benign pediatric dermatological lesion that occurs in children between 8 months and 13 years of age. The pathogenesis of IFAG is still unclear but it is likely to be associated with granulomatous rosacea in childhood. Here we describe a case of IFAG in a 13-year-old boy who showed a dramatic response to oral doxycycline and topical metronidazole, which supports the hypothesis that IFAG may belong to the spectrum of rosacea.

(C) 2016 The Author(s)

Published by S. Karger AG, Basel
\end{abstract}

\section{Introduction}

Idiopathic facial aseptic granuloma (IFAG) is a rare, benign dermatological lesion that occurs specifically in children. IFAG was first described by a group of French dermatologists who used the name 'pyodermite froide du visage' because it resembles a cold abscess of the 
face [1]. The condition is characterized by chronic, painless, and red-to-violaceous nodules of a soft or elastic consistency on the face. In most cases, the nodule is solitary, typically located on the cheeks or eyelids, and resolves spontaneously within 11 months on average [2]. The pathogenesis of IFAG remains unclear, although some authors have postulated that it could belong to the spectrum of childhood rosacea $[3,4]$. Here we describe a case of IFAG in a 13year-old boy who showed a dramatic response to oral doxycycline and topical metronidazole, which supports the hypothesis that IFAG may represent a subtype of pediatric rosacea.

\section{Case Presentation}

A healthy 13-year-old boy was referred to our department for evaluation of an asymptomatic nodule on the right cheek. The nodule had appeared 3 months before and had been treated with systemic amoxicillin and topical and systemic steroids without improvement. The child did not report any trauma or an insect bite. Dermatological examination of the right cheek revealed a $25-\mathrm{mm}$, solitary, red-to-violaceous nodule of an elastic consistency (fig. 1). Upon physical examination, the child was afebrile and had no palpable regional lymphadenopathy. A 3-mm punch biopsy of the nodule was performed. Histological examination revealed a dermal inflammatory infiltrate consisting of histiocytes, lymphocytes, neutrophils, eosinophils, and plasma cells (fig. 2). No polarizable foreign bodies were identified. The cytokeratin AE1/AE3 stain was negative. Special stains, including Gram, Ziehl-Neelsen, periodic acid-Schiff, and Grocott were all negative. On the basis of the historical, clinical, and histologic findings, a diagnosis of IFAG was established. Treatment with oral doxycycline $(100 \mathrm{mg} /$ day $)$ and topical metronidazole was started. The nodule regressed within 2 weeks and resolved almost completely after 6 weeks (fig. 3).

\section{Discussion}

IFAG occurs in children between 8 months and 13 years of age. It is characterized by red-purple nodules usually located in a particular triangle-shaped cheek area that is delimited by the external limit of the orbit, labial angle, and ear lobe. There is no predisposing factor, no family history, and no evidence for a microbial cause [2]. The differential diagnosis of IFAG includes benign tumors, such as pilomatricomas, dermoid or epidermoid cysts, chalazions; bacterial, mycobacterial, fungal or parasitic infections; pyogenic granulomas; Spitz nevi; xanthogranulomas, and vascular malformations or hemangiomas $[1,2,5]$. The pathogenesis of IFAG is still unclear, but it is likely to be associated with granulomatous rosacea in childhood [6]. Another hypothesis is that IFAG could be an inflammatory reaction appearing around an embryological residue or the remnant of an epidermal cyst, although our case and previous histological studies do not support this hypothesis [2, 4]. Furthermore, children with IFAG have a greater risk of developing rosacea, particularly ocular rosacea [6]. Similarly, a recent multicenter prospective study of 38 children with IFAG revealed that 16 children $(42.1 \%)$ were found to have at least two clinical signs of rosacea, most commonly flushing and papulopustules [4]. Histologically, IFAG lesions are similar to those of a foreign-body granuloma or infection [7]. When performed, ultrasound examination showed a welldemarcated, solid, hypoechoic dermal lesion without calcium deposits $[1,8]$.

In the present case, we observed a dramatic response to oral doxycycline and topical metronidazole, which are common effective medications used to treat rosacea. Taken to- 
gether, these findings reinforce the hypothesis that IFAG may belong to the spectrum of rosacea. In addition, this case supports the use of valid treatment options available in childhood rosacea to accelerate the involution of IFAG.

\section{Statement of Ethics}

The authors have no ethical conflicts to disclose.

\section{Disclosure Statement}

The authors declare that they have no conflicts of interest to disclose.

\section{References}

1 Roul S, Léauté-Labrèze C, Boralevi F, Bioulac-Sage P, Maleville J, Taïeb A: Idiopathic aseptic facial granuloma (pyodermite froide du visage): a pediatric entity? Arch Dermatol 2001;137:1253-1255.

-2 Boralevi F, Léauté-Labrèze C, Lepreux S, Barbarot S, Mazereeuw-Hautier J, Eschard C, Taïeb A; Groupe de Recherche Clinique en Dermatologie Pédiatrique: Idiopathic facial aseptic granuloma: a multicentre prospective study of 30 cases. Br J Dermatol 2007;156:705-708.

-3 Baroni A, Russo T, Faccenda F, Piccolo V: Idiopathic facial aseptic granuloma in a child: a possible expression of childhood rosacea. Pediatr Dermatol 2013;30:394-395.

-4 Prey S, Ezzedine K, Mazereeuw-Hautier J, Eschard C, Barbarot S, Boralevi F, Taïeb A, Léauté-Labrèze C; Groupe de Recherche Clinique en Dermatologie Pédiatrique: IFAG and childhood rosacea: a possible link? Pediatr Dermatol 2013;30:429-432.

-5 Hiraldo-Gamero A, Vera-Casano A, Sanz-Trélles A: Idiopathic facial aseptic granuloma. Actas Dermosifiliogr 2013;104:635-636.

6 Neri I, Raone B, Dondi A, Misciali C, Patrizi A: Should idiopathic facial aseptic granuloma be considered granulomatous rosacea? Report of three pediatric cases. Pediatr Dermatol 2013;30:109-111.

7 Gonzalez Rodriguez AJ, Jorda Cuevas E: Idiopathic facial aseptic granuloma. Clin Exp Dermatol 2015;40:298-300.

-8 Zitelli KB, Sheil AT, Fleck R, Schwentker A, Lucky AW: Idiopathic facial aseptic granuloma: review of an evolving clinical entity. Pediatr Dermatol 2015;32:e136-e139. 


\section{Case Reports in Dermatology}

\begin{tabular}{l|l}
\hline Case Rep Dermatol 2016;8:197-201 \\
\hline $10.1159 / 000447624$ & $\begin{array}{l}\text { @ 2016 The Author(s). Published by S. Karger AG, Basel } \\
\text { www.karger.com/cde }\end{array}$ \\
\hline
\end{tabular}

Orion et al.: Idiopathic Facial Aseptic Granuloma in a 13-Year-Old Boy Dramatically Improved with Oral Doxycycline and Topical Metronidazole

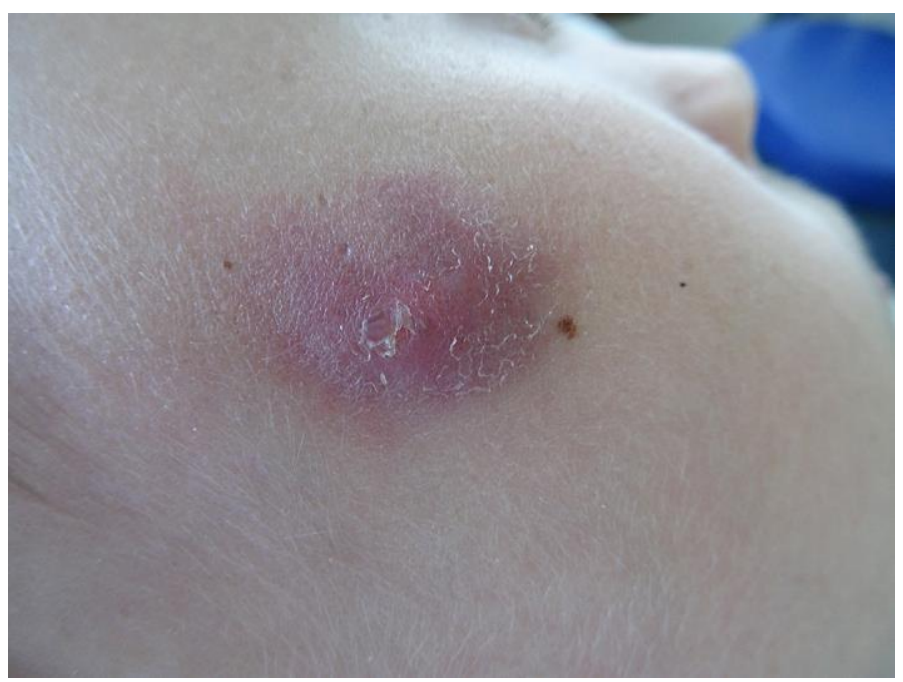

Fig. 1. Clinical presentation of an asymptomatic red-to-violaceous nodule on the right cheek.

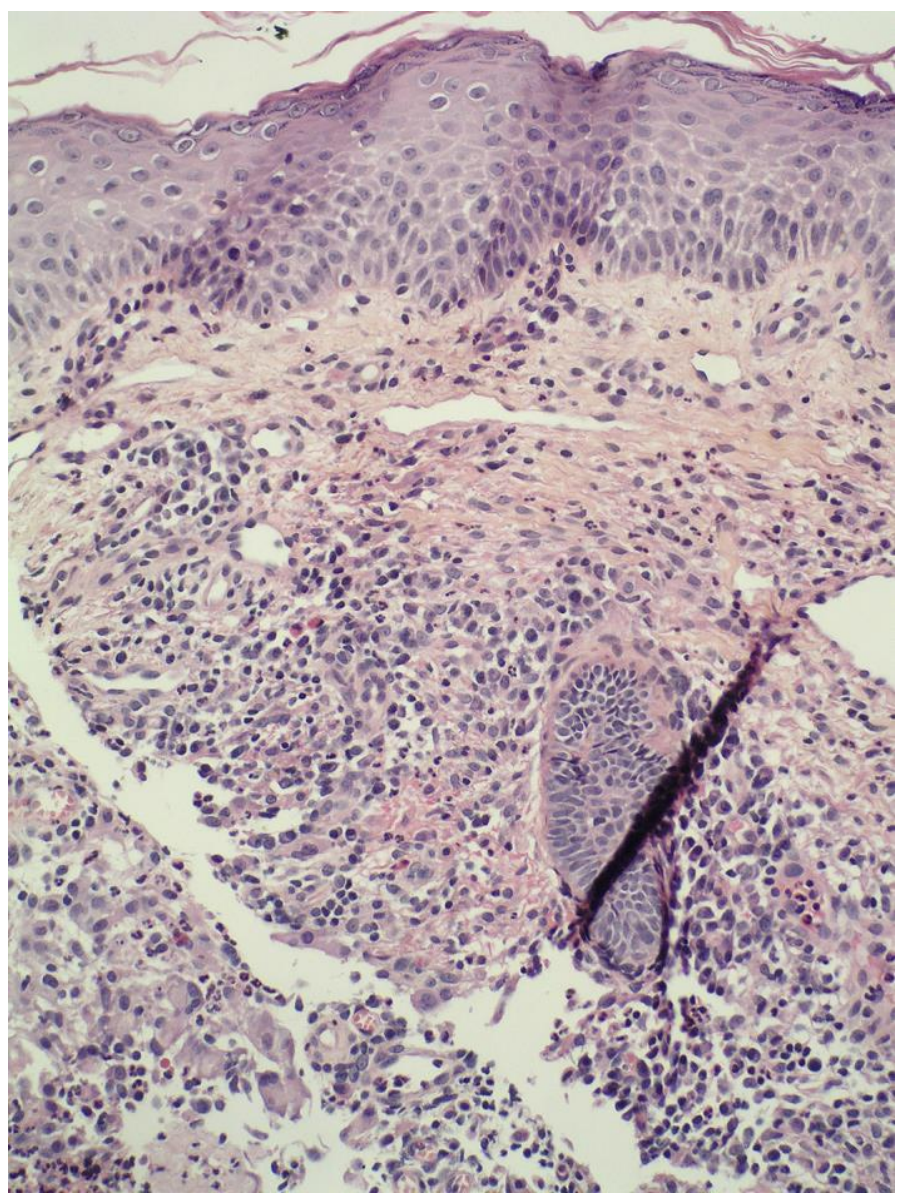

Fig. 2. Histological examination showing a polymorphic inflammatory infiltrate in the dermis composed of histiocytes, lymphocytes, neutrophils, eosinophils, and plasma cells. HE. $\times 200$. 


\section{Case Reports in Dermatology}

(C) 2016 The Author(s). Published by S. Karger AG, Basel ww.karger.com/cde

Orion et al.: Idiopathic Facial Aseptic Granuloma in a 13-Year-Old Boy Dramatically Improved with Oral Doxycycline and Topical Metronidazole

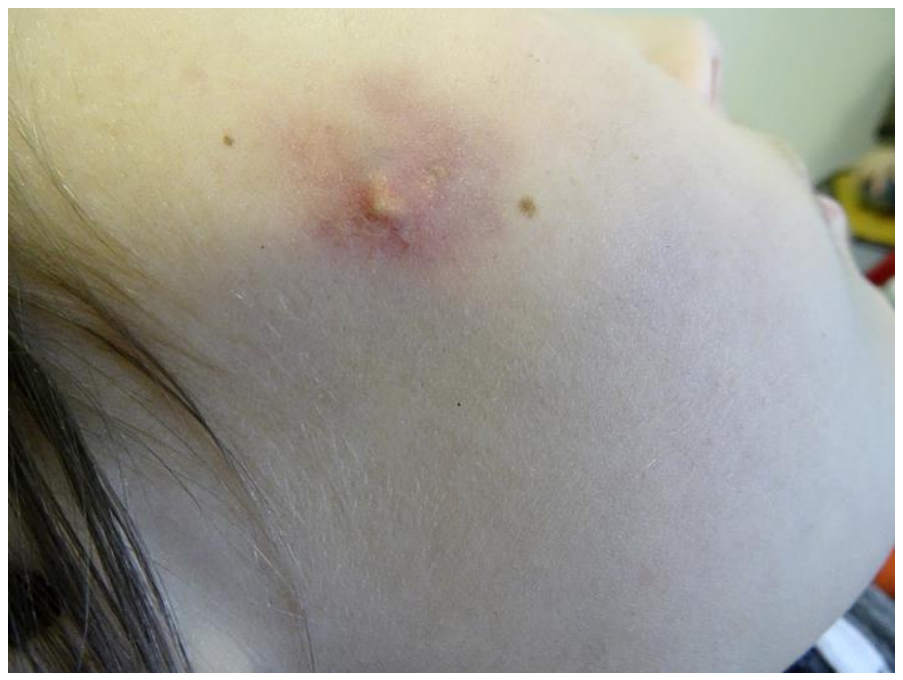

Fig. 3. The nodule resolved almost completely after 6 weeks of treatment with oral doxycycline and topical metronidazole. 